\title{
Estratégia de marketing digital para unidades informacionais: estudo dos websites de Arquivos e Bibliotecas Públicas Estaduais
}

\author{
Digital marketing strategie for informational units: Comparative between State Public \\ Archives and Libraries websites
}

Luan Giroto

Mestrando do Programa de Pós-Graduação em Ciência da informação da Universidade Estadual Paulista "Júlio de Mesquita Filho" - UNESP Campus de Marília.

E-mail: luan.giroto@gmail.com

Rosangela Formentini

Professora do Departamento em Ciência da informação da Universidade Estadual Paulista "Júlio de Mesquita Filho" - UNESP Campus de Marília.

E-mail: rcaldas@ marilia.unesp.br

\section{Resumo}

Os arquivos e bibliotecas podem utilizar de um arcabouço de marketing digital para aproximação do público-alvo, oportunidade de aprimoramento de serviços online além de, disseminar a informação no ambiente digital em prol do desenvolvimento de comunidades. Existem poucos estudos existentes dessa natureza na área de ciência da informação. Entende-se que estudar o marketing digital em websites de arquivos e bibliotecas poderia ocorrer uma apropriação de conteúdo, do acesso informacional e a disponibilização de produtos e serviços. O objetivo da investigação procurou verificou o marketing digital presente nos arquivos e bibliotecas públicas estaduais. A abordagem qualitativa do tipo descritiva e explicativa. O método utilizado foi a pesquisa documental dos websites das instituições. Com o uso de indicadores analisou-se as páginas de trinta e três websites. Posteriormente, realizou-se uma análise comparativa entre as páginas verificadas. Os arquivos e as bibliotecas, ao utilizarem-se do marketing digital passam a integrar estrategicamente um cenário de maior disponibilização de informações, abordando inúmeras vantagens para a visibilidade institucional, promoção e reconhecimento das esferas públicas.

Palavras-chave: Marketing digital. Arquivos públicos estaduais. Bibliotecas públicas estaduais.

\begin{abstract}
The web as a context of possibilities of communication and informational interaction allows to potentiate cultural equipment such as Public State Archives and Libraries in the context of visibility and democratic participation. The archives and libraries can use a digital marketing framework to approach the target audience, the opportunity to improve online services and Disseminate information in the digital environment for the development of communities. The research is justified by the few existing studies of this nature in the area of information science and it is believed that the results corroborate in the development of the dissemination of information through the knowledge of digital marketing for cultural equipment. Thus, the research problem focuses on the dissemination of information through digital marketing indicators on websites of information units. The objective of the study proposed to raise conceptual aspects of digital marketing for archival websites and libraries. Thus, the general indicators are: User Attraction, Interaction, Content, Relationship, Personalization and Promotion. The study is a qualitative approach with the documental research methodology of the institutions' websites. Subsequently, a comparative analysis was performed between the verified pages. The Archives and libraries, using digital marketing and, in the face of new social, technological, economic and contextual paradigms, strategically integrate a set of greater availability of information, addressing innumerable advantages for institutional visibility, promotion and recognition Of public spheres.
\end{abstract}

Keywords: Digital marketing. Public Archive. Public libraries. Dissemination of information. Indicators.

InCID: R. Ci. Inf. e Doc., Ribeirão Preto, v. 8, n. 2, p. 144-162, set. 2017/fev. 2018

DOI: 10.11606/issn.2178-2075.v8i2p144-162 


\section{Introdução}

A dimensão digital enquanto perspectiva de difusão informacional para bibliotecas e arquivos torna-se um estímulo para o compartilhamento e ao acesso da informação na web. $\mathrm{O}$ marketing, por sua vez, auxilia enquanto ciência interdisciplinar, no atendimento aos desejos e as necessidades de sujeitos que se apropriam da informação.

Neste contexto, o marketing digital surge como um incentivo à promoção das instituições, agregando fatores estratégicos para a exploração e o aprimoramento da atuação de arquivos, bibliotecas e museus na conjuntura digital.

O arquivo enquanto uma instituição orgânica no contexto do documento, necessita introjetar ações que possam contribuir para as formas de melhorias no acesso informacional. As instituições arquivísticas poderiam atuar conjuntamente as necessidades oriundas nas esferas políticas, econômicas, tecnológicas e sociais. Diante disso, deveriam ocorrer novas reflexões perante acerca da possibilidade de ações frente ao documento e ao paradigma patrimonialista das instituições. Para Araújo (2014) o arquivo deve possuir um modelo funcionalista e positivista uma vez que se insere em um sistema orgânico vivo e funcional.

Paralelamente, as bibliotecas devem possuir produtos e serviços que sejam um reflexo da sua inserção na sociedade a qual está inserida, para uma melhor qualidade de vida e auxilio no funcionamento do Estado e na aproximação e disponibilização de conteúdos informacionais que agreguem valor ao sujeito enquanto cidadão e assim, compõem uma nova atuação das unidades como agentes influenciadores no sistema social.

A pesquisa justifica-se diante dos poucos estudos existentes dessa natureza na área de ciência da informação e acredita-se que os resultados corroboram no desenvolvimento da disseminação da informação mediante o conhecimento do marketing digital para os equipamentos culturais.

Neste aspecto, o objetivo da investigação procurou verificar o marketing digital presente nos arquivos e bibliotecas públicas estaduais. Entende-se que ao estudar o marketing digital em tais instituições pode proporcionar uma visibilidade e reconhecimento institucional, auxiliando no enfoque das necessidades existentes para cada comunidade brasileira.

Participaram do estudo, 33 instituições públicas estaduais, sendo 13 Arquivos e 20 Bibliotecas. Os Arquivos Públicos Estaduais têm como função fundamental o desenvolvimento 
e a implementação de políticas públicas no que tange a disseminação da informação histórica e administrativa referente ao Estado e da Nação. Por sua vez, o marketing digital auxiliaria na visibilidade das Bibliotecas Públicas Estaduais, promovendo a disponibilidade de recursos em prol da inserção do indivíduo em sociedade.

O estudo utilizou os indicadores do marketing digital, propostos por Ferreira (2016) Atração de usuários, Interação, Conteúdo, Relacionamento, Personalização e Promoção -, a fim de identificar a disponibilização de recursos digitais em websites de Arquivos e Bibliotecas Públicas Estaduais. A abordagem foi qualitativa, do tipo descritiva e explicativa. O método utilizado foi a pesquisa documental para que, houvesse uma comparação entre as instituições de modo que, auxiliam á ambas na visibilidade, promoção, disponibilização e novos recursos em prol do acesso da comunidade.

Considera-se que o ambiente digital proporciona novas configurações para a atuação de entidades públicas como benefício para a população. Concomitantemente, o marketing digital quando utilizado nos espaços digitais de ambas as unidades, tem impactos na construção das imagens e dos serviços utilizados pelos sujeitos, permitindo uma forma crítica e reflexiva na medida em que geram conhecimentos. Apesar dos baixos índices de uso e potencialidade do marketing digital nos websites brasileiros, as instituições que utilizam de estratégias, reforçam o vinculo de relacionamento com o usuário e garantem melhor vida útil na internet favorecendo os clientes internos e externos do arquivo e da biblioteca.

\section{Marketing digital para arquivos e bibliotecas}

Para Kotler (1998, p. 27), Marketing representa "um processo social e gerencial pelo qual indivíduos e grupos obtêm o que necessitam e desejam através da criação, oferta e troca de produtos". A conceituação de Marketing adere-se a novos princípios, conforme as mudanças nas esferas globais. Para uma ciência que se estrutura em diversas áreas do saber como economia, sociologia e psicologia, o marketing abrange conjuntos de conhecimentos capazes de atender o mercado, o comportamento das pessoas e a legislação vigente, destacando-se em determinado nicho.

Neste contexto, com a forte influência da internet em todo globo, abre-se novas oportunidades de desenvolvimento para o marketing em prol de uma comunicação mais efetiva e próxima com o sujeito. Este, por sinal, "passa a ter mais facilidade na emissão sobre o produto, [...] intensificando a interação entre consumidor e proprietário" (CINTRA, 2010, p.7). 
As pessoas utilizam cada vez mais ferramentas da internet para consumo e investimento. De acordo com a International Telecommunications Union (ITU), quase 3 bilhões de pessoas (40\% da população mundial) têm acesso à internet. O índice Global Web informou também que, $91 \%$ desses internautas possuem um laptop ou computador e que $80 \%$ possuem um smartphone ${ }^{1}$. A nova fase digital permeia oportunidades estratégicas para as organizações, ampliando o fluxo de informações disponibilizadas em rede.

Naik e Shivalingaiah (2008, p. 499) abordam que com a evolução da Web, a experiência de troca de informações é cada vez mais importante perante os muitos aspectos da vida: educação, emprego, governo, comércio, saúde e outros. "A web é um sistema de documentos hipertexto interligados acessados por meio da internet".

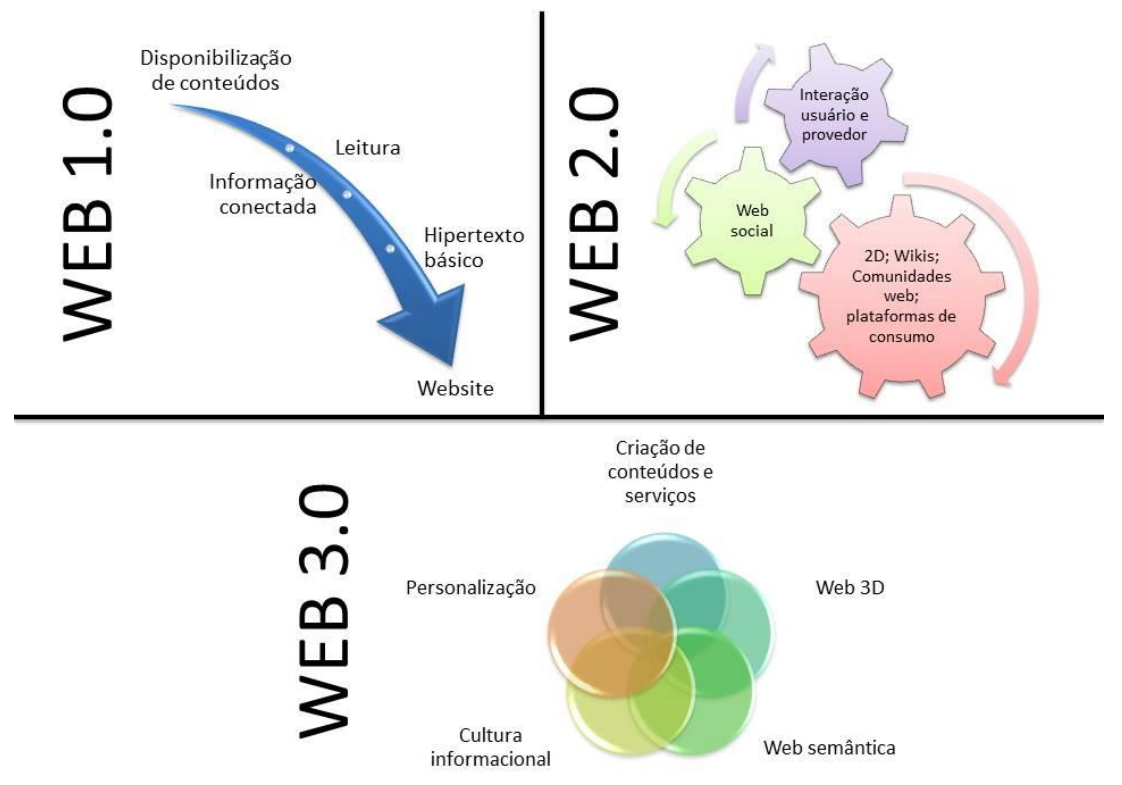

Figura 1 - Evolução da WEB

Fonte: Elaborado pelos Autores.

A figura 1 representa as características da web mediante sua evolução. Segundo Naik e Shivalingaiah (2008), a primeira etapa, a web 1.0, foi de Informações disponibilizadas na internet. A Web 2.0 é sobre conectar pessoas colocando o "eu" no usuário. A Interface e os "nós" em uma teia de participação social. A próxima etapa, a web 3.0, trata-se de representar significados, conectar conhecimento e colocá-los em prática útil e agradável. Com isso, o marketing entra em um processo de reinvenção, principalmente no contexto das mídias sociais da web 2.0.

\footnotetext{
${ }^{1}$ Disponível em $<$ http://www.tecmundo.com.br/internet/80533-3-2-bilhoes-pessoas-tem-acesso-internetsegundo-relatorio.htm>. Acesso em: 04 nov. 2016.
} 
Para Crittenden e Crittenden (2015) os websites e as mídias sociais criam oportunidades de diálogos centralizados nas necessidades e desejos dos indivíduos, bem como nas campanhas mais criativas e atualizáveis; por consequência, tornam-se as principais forças do marketing digital.

Kaplo e Kaneberg (2015) ao conceituar o marketing digital, refletem que este tornou-se um canal efetivo para atingir os indivíduos e um conhecimento estratégico para instituições em processo de recrutamento ou que tentam inovar produtos por meio de campanhas na internet. Strauss e Frost (2012, p. 6) definem marketing digital como um conhecimento que "[...] consiste no uso da tecnologia de informação para atividades de marketing, e os processos para criar, comunicar, desenvolver e compartilhar ofertas que agregam valor aos clientes, parceiros e a sociedade em geral".

De acordo com Cintra (2010), as estratégias de marketing digital têm se mostrado eficazes, principalmente para aqueles que cruzam os negócios físicos com a loja virtual. Entretanto, segundo uma pesquisa realizada no Brasil pela revista Guia Mais com 1.200 micro, pequenos e médios empresas, apontou-se que $7 \%$ dos entrevistados anunciam online e somente $22 \%$ possuem um website oficial como garantia de presença na web ${ }^{2}$.

Ocorre que, enquanto as mídias tradicionais permanecem importantes para a promoção e ações de comercialização, é preciso considerar uma nova realidade do Marketing.

Para desenvolver o marketing digital Zeisser e Waitman (1998) apontam cinco possibilidades de aplicações, são elas:

\begin{abstract}
Atrair usuários 2. Os usuários devem exercer participação e interesse 3. Garantir que os usuários retornem para o aplicativo 4. Saber sobre suas preferências 5. Relativa volta para os usuários fornecerem interações personalizadas que representam o verdadeiro "valor bolha" de marketing digital. (ZEISSER; WAITMAN, 1998, p. 34, tradução nossa).
\end{abstract}

Na perspectiva dos equipamentos culturais como arquivos e bibliotecas, o conhecimento de marketing na web institui probabilidades de disseminar a informação de maneira mais rápida e efetiva mediante a tecnologia. $\mathrm{Na}$ internet, uma das ferramentas mais expansivas e agregadoras de conteúdos utilizadas por essas instituições são os websites e as mídias sociais.

É notório que as unidades informacionais mudaram sua concepção de acesso e disseminação, pois seus usuários diferenciaram-se e, consequentemente, buscam por novos

\footnotetext{
${ }^{2}$ Disponível em <http://pme.guiamais.com.br/apenas-7-das-micro-pequenas-e-medias-empresas-anunciam-naweb/>. Acesso em: 04 nov. 2016.
} 
elementos que agregam conhecimento e competitividade direta e indireta. "O usuário ainda é visto mais como objeto do acesso a informação do que como sujeito do processo de sua transferência” (MARIZ, 2012, p. 29).

Nesta conjuntura, a administração que recolhe, organiza e dissemina conhecimento, necessita encontrar diretrizes que mediem o produto ao indivíduo. Segundo Kelly et al. (2015) o avanço dos websites estáticos para um contexto participativo e interativo proporciona oportunidades potenciais de co-criação de produtos e serviços, em uma nova realidade do Marketing como fator mutável ao seu mercado.

\section{Dimensão política da disseminação da informação em contextos digitais}

Novos formatos de pensar a comunicação e a informática estão modificando o que conhecemos por processo de aprendizagem. Para Santos (2004, p. 6) "O desenvolvimento das tecnologias da informação cria novas possibilidades em relação aos processos informacionais". Entre eles, destacam-se questões relativas ao acesso à informação e fluxos informacionais em contextos híbridos.

Ao se pensar acerca das unidades informacionais às quais o acesso à informação é referência para um novo contexto social, que interage as localidades em prol do desenvolvimento e crescimento diferenciados, entende-se que a informação é o diferencial na geração do conhecimento (SILVA; CALDAS, 2016, p. 147).

Para as autoras, os equipamentos culturais (arquivos, bibliotecas e museus) estão em processos de mutação que parte da condição tradicional para um estado híbrido e que, permitem novos parâmetros de interação com o sujeito.

O sujeito compreende o direito à informação como reforço do conhecimento que necessita para cumprir o papel de cidadão, mas esbarra em questões legislativas enquanto ordem de disponibilização e acesso em mídias e materiais físicos e na web conforme a figura 2. 


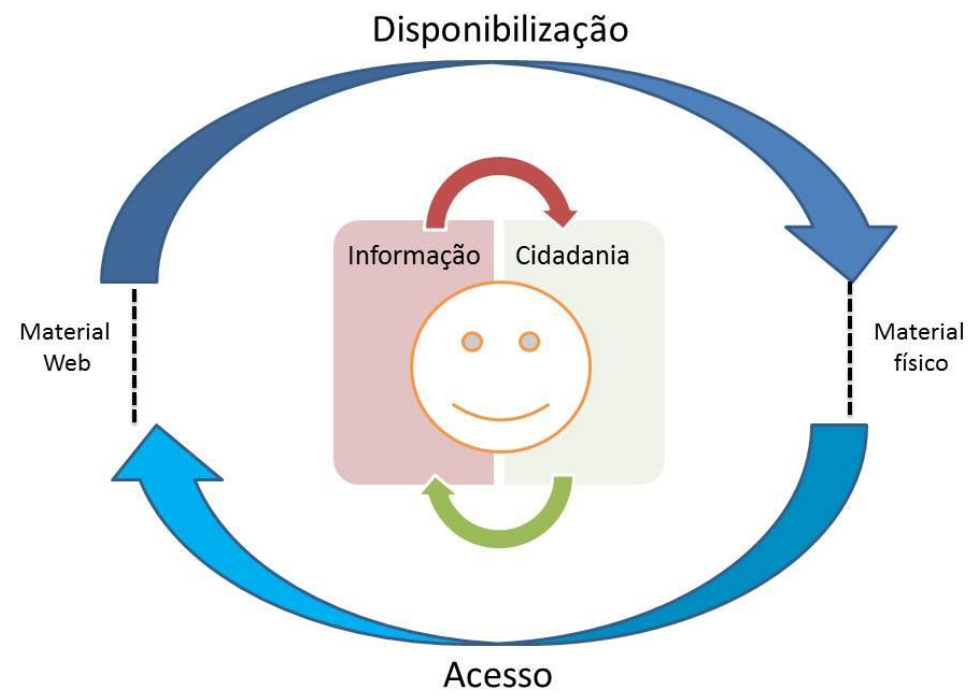

Figura 2 - O ciclo realizado entre disponibilização e acesso informacional Fonte: Elaborado pelos Autores

Como demonstrado na figura 2, o acesso e a disponibilidade dos materiais físicos e da web para os cidadãos são prejudicados mediante o contexto da falta de estrutura politica, econômica, social e tecnológica. Nisso, interfere no ciclo continuo de conhecimento e reflete nas instituições provedoras de tais informações.

\begin{abstract}
Nesse sentido, a cidadania presume, entre outros, o direito (de cada brasileiro) à informação, apesar de o seu pressuposto sobre a educação e a cultura ainda estar longe de atender as necessidades reais da sociedade, diferentemente daquelas parcas necessidades expressas de que se falava acima. (BARROS, 2003, p. 22).
\end{abstract}

Essas mudanças levam a novos parâmetros sociais, que exclui a importância de tempo e distância (SANTOS, 2004); e exige novas estratégias e ações que transmitam a informação em formato digital. O novo paradigma emergente amplia a perspectiva de registro do fenômeno social e humano para uma compreensão da informação como matéria-prima em meio às influências das tecnologias da informação e comunicação.

Por isso, informação é compreendida como

[...] representações mentais codificadas (símbolos significantes) socialmente contextualizadas e passíveis de serem registadas num qualquer suporte material (papel, filme, banda magnética, disco compacto, etc.) e, portanto, comunicadas de forma assíncrona e multidirecionada (SILVA; RIBEIRO, 2002, p. 37).

Neste contexto, disseminar informação em ambiente digital presume que a informação foi digitalizada e transferida para outra conjuntura. "O processo de disseminar informações envolve dois aspectos fundamentais: o pressuposto de que há informações a serem disseminadas 
e que o próprio processo envolve estratégias e técnicas de comunicação" (BARROS, 2003, p. $53)$.

Diante deste cenário, muitas questões estão por serem formuladas. A própria atividade informacional deve-se adequar aos formatos digitais para agregar valor nesta sociedade em rede apresentada por Cardoso e Castells (2005). A ampliação de diversas fontes de informação na internet propaga um crescimento acelerado e mutáveis de informações para atender demandas especificas de cada indivíduo. Assim, as unidades informacionais tendem a cumprir um papel social de disponibilizar informações das esferas públicas de poder para o desenvolvimento social.

Prover acesso on-line, estruturar instrumentos de pesquisas de maior qualidade, conhecer seu usuário, adotar estratégias de disseminação mais agressivas, fazer uso das novas tecnologias da informação representam um conjunto de demandas que nos impulsionam na adoção de novos caminhos (SANTOS, 2004, p.8).

Ao mesmo tempo, refletem questões sobre o profissional da informação perante as tecnologias de disseminação. Esta interação com um novo público em diferentes áreas do conhecimento mediante aos recursos digitais, aproximam objetivos comuns de acesso e busca por informação sendo que, torna-se complexo uma estruturação de criação e potencialidade mediante os equipamentos culturais.

\section{Metodologia}

A abordagem metodológica é qualitativa, do tipo descritiva e explicativa. O método utilizado foi a pesquisa documental. A escolha do método deu-se diante do objetivo da investigação que visou aplicar os indicadores de marketing digital em websites de Arquivos e Bibliotecas Estaduais do Brasil.

A coleta de dados foi realizada nas páginas oficias das instituições disponibilizadas na internet no ano de 2016. Segundo Dziekaniak et al (2006), o website tem por objetivo tornar disponíveis os produtos e serviços listados ano ambiente web para satisfazer as necessidades do usuário e da instituição em disponibilizar informações.

No que tange a pesquisa documental, "o documento como fonte de pesquisa pode ser escrito e não escrito, tais como filmes, vídeos, slides, fotografias ou pôsteres". (SÁ SILVA; ALMEIDA; GUINDANI, 2009, p. 5). Esses documentos são utilizados como fontes de informações para esclarecer determinadas questões e interesses de acordo com o pesquisador. 
Assim, buscou-se investigar com os indicadores de marketing digital propostos por Ferreira (2016), o tratamento informacional na disponibilização e acesso de conteúdos em rede.

O universo de pesquisa teve a totalidade de trinta e três websites. Entre as quais, 13 são referentes a Arquivos Públicos Estaduais disponíveis no Conselho Nacional de Arquivos (CONARQ) e 20 de Bibliotecas Públicas Estaduais acessadas por meio do Sistema Nacional de Bibliotecas Públicas (SNBP). Não participaram da pesquisa 19 instituições sendo que 14 são referentes aos arquivos e cinco para bibliotecas. Os endereços eletrônicos estavam indisponíveis no website do CONARQ e da SNBP.

A partir do contexto de indicadores para marketing digital, foi realizado o levantamento individual dos websites a equivalência como demonstrado nos websites das unidades informacionais. A escolha pelos indicadores por Ferreira (2016) deu-se mediante atender a proposta da pesquisa. Ressalta-se que os indicadores foram baseados em Chleba (1999), Zeisser e Waitman (1998), Strauss e Frost (2012). Por isso, foram propostos: Atração de usuários; Interação; Conteúdo, Promoção; Personalização e Relacionamento.

Para a análise de dados, foi compreendido a necessidade de agregar especificidades para representar o marketing digital em tais ambientes. A Figura 3 é possível perceber a descrição dos indicadores para análise posterior dos websites.

No tangente do indicador Atração de usuários, utilizaram-se de descritores como Layouts, existência de logomarcas, a disponibilização de história institucional e um menu com serviços e produtos ofertados pelo website. No indicador Interação, verificaram-se a existência de chats online, comentários via mídia social, a possibilidade de prestação de serviços digitais e um endereço eletrônico acessível. No Conteúdo, apuraram-se a atualização constante de informações na página oficial das instituições, a apresentação de conteúdos específicos do arquivo e da biblioteca além de hiperlinks com outros locais e conteúdos digitais. Quanto a Promoção, pesquisaram-se o uso de campanhas publicitárias que poderiam auxiliar na divulgação digital de produtos e serviços ofertados pelas instituições e o uso de hipermídias como vídeos e canais externos ao website oficial. Em relação a Personificação, o cadastro de usuários, a pesquisa personalizada e os serviços personalizadas foram o que obtiveram maiores destaques em relação ao uso nesta categoria de marketing digital. Por último indicador visualizado, o Relacionamento, foi descrito como vínculo com mídias sociais e a disponibilização de perguntas frequentes que poderiam auxiliar no tratamento de busca e recuperação da informação nas páginas pesquisadas. 


\begin{tabular}{|c|c|}
\hline $\begin{array}{l}\text { Atração de } \\
\text { usuários }\end{array}$ & $\begin{array}{l}\text {-Layouts } \\
\text {-Logomarcas } \\
\text {-História institucional }\end{array}$ \\
\hline Interação & $\begin{array}{l}\text { - Chats } \\
\text { - Interação via Midias Sociais } \\
\text { - Serviços online } \\
\text {-E-mail }\end{array}$ \\
\hline Conteúdo & $\begin{array}{l}\text {-Atualização } \\
\text {-Conteudos Específicos } \\
\text { - Hiperlinks/ outros formatos midiáticos }\end{array}$ \\
\hline Promoção & $\begin{array}{l}\text { - Campanhas } \\
\text {-Uso de hipermídias }\end{array}$ \\
\hline Personalização & $\begin{array}{l}\text { - Cadastro do usuário } \\
\text {-Pesquisa personalizada } \\
\text {-Serviços personalizados }\end{array}$ \\
\hline Relacionamento & $\begin{array}{l}\text {-Vínculo com Mídias Sociais } \\
\text {-Perguntas frequentes }\end{array}$ \\
\hline
\end{tabular}

Figura 3 - Descrição dos Indicadores de Marketing Digital Fonte: Elaborado pelos Autores.

Posteriormente, realizou-se uma comparação entre os Arquivos e as Bibliotecas por meio dos mesmos indicadores, a fim de averiguar o uso potencial de conhecimentos do marketing digital para a disseminação da informação na internet. Entende-se que a pesquisa não reforça a competição entre as entidades, mas sim, investiga um novo formato de disponibilização de conteúdos que possibilita um retorno de visibilidade, resultados rastreáveis, alcance global e campanhas mais interessantes para os equipamentos culturais.

\section{Análise dos resultados}

Os arquivos e as bibliotecas públicas estaduais deveriam ser representados mediante suas páginas web, como proposta essencial de transparência, acesso à informação e paradigma pós-custodial. Ribeiro (2005) destaca que a tecnologia digital trouxe, em grande proporção, a simbiose estática e duradoura do documento em suporte papel para uma a mudança de objeto, voltado para a informação.

No gráfico 1, observa-se que existem níveis de desempenho para cada indicador de marketing digital. Entre os indicadores o que mais se desponta é atração de usuários, sendo 23\% para arquivos e $21 \%$ para bibliotecas. Foram verificados, os vinte e quatro websites que compunham o universo de pesquisa. 
Gráfico 1 - Indicadores de Marketing Digital em Arquivos e Bibliotecas

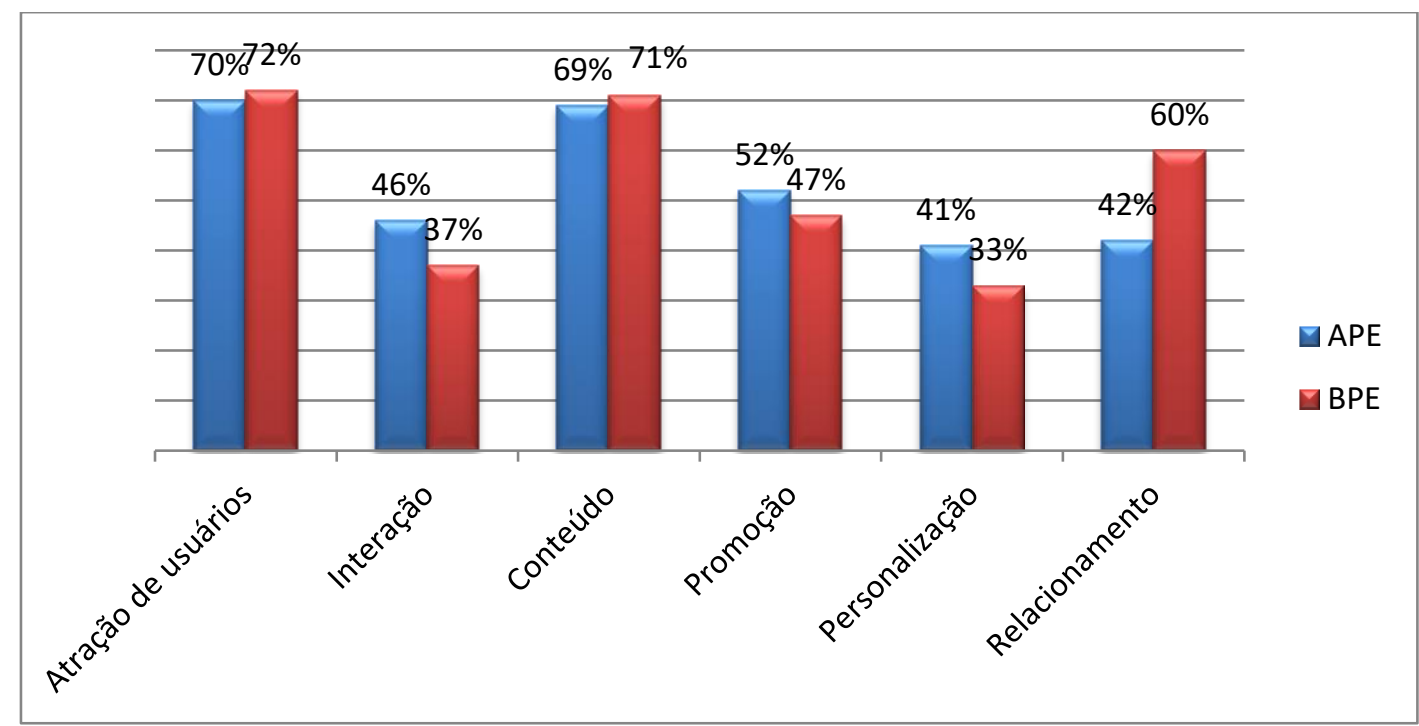

Fonte: Elaborado pelos Autores

No campo analítico do marketing digital, o sujeito constrói perante a interface da página oficial do Arquivo e/ou Biblioteca. O pensamento, segundo Santaella (2001), está diretamente ligado à linguagem, na medida em que a mente modula o que vemos, pensamos e falamos, em cognitivismos pessoais.

Embora a pouca diferença entre as duas instituições, as Bibliotecas Públicas Estaduais (BPE) utilizam com mais facilidade a apresentação institucional em comparação com os Arquivos Públicos Estaduais (APE). Nesta conjuntura, destacou-se a importância da imagem das instituições enquanto prestadoras de serviços públicos e com isso, a trabalho atrativo deve contemplar um Layout diferenciado, uma logomarca que represente o órgão público e, para fins históricos, exibir a trajetória e construção da instituição na nação. Validou-se, assim, que 70\% das APE estão sendo prejudicadas por situar-se às páginas de secretária do Estado, agregandose um determinado espaço para seus serviços sem possuir uma identidade que possibilite uma melhor apresentação e um design efetivo de comunicação da instituição.

A forma como a informação é apresentada ao usuário refletirá na comunicação do público para com os conteúdos do website. Parece lógico, mas a interação - outro indicador considerado - tende a provocar rupturas de transmissão de dados, informação e conhecimento na era digital (CASTELLS, 1999). Assim, 47\% de interação estão sendo utilizadas em arquivos e $37 \%$ em bibliotecas. Por meio de recursos interativos nas páginas digitais, o sujeito tem um maior interesse em pesquisar e interagir com os serviços disponíveis no website. 
Para os Arquivos, a ideia de Chats ainda é inexistente. Ressaltou-se que os e-mails continuam como meio tradicional de serviços utilizados por ambas as instituições. Enquanto que a participação do indivíduo é mais efetiva em serviços online de pesquisas em Arquivos. Todavia, ainda é baixa a interoperabilidade entre a informação analógica e digital que supra as necessidades do público potencial na web.

Compreende-se a necessidade de relacionamento do documento com o contexto tecnológico de Hardware, Software e suporte, além de práticas de gestão e preservação voltadas para o Digital. Santos e Flores (2016) apontam que, as alterações do ambiente digital evidenciaram novas estruturas de atribuição da informação, por meio de metadados e repositórios digitais.

No terceiro indicador verificado - conteúdo - visualizaram-se os produtos que os APEN e as BPE ofertavam em seus respetivos website. Com $71 \%$ de conteúdos em bibliotecas e $69 \%$ em arquivos, ressaltou-se que as páginas das instituições que visam a informação como produto tendem a ser monitorados e preenchidos constantemente a fim de, oferecer subsídios direcionados aos usuários e outros órgãos do Estado. (MARIZ, 2012).

A falta de atualização analisada nestes ambientes dificulta o pleno exercício do cidadão, tornando-se “informações alienígenas" (AMARAL, 1998), que são incapazes de atualizar-se perdendo parte da autonomia e prestígio como agregador de acesso on-line. O conhecimento de marketing de conteúdos poderia alavancar as informações nestes website, uma vez que, incorporam as necessidades dos sujeitos com a linguagem necessária para comunicação digital.

No indicador promoção, os arquivos utilizaram-se de 52\% de todo recurso disponível nesta categoria, enquanto que nas bibliotecas é ainda menor o índice, com 47\% apenas. A utilização de banners, vídeos institucionais e mídias, em geral, podem proporcionar uma função promocional e criativa de informações na página. Caldas (2005) salienta que a imagem de uma unidade de informação desenvolvida no processo social, politico e educacional capacita a instituição no oferecimento de trocas em bens tangíveis e intangíveis ao consumidor e principalmente em oferecer bens na forma de produtos gerados pela demanda do mercado.

Foram encontrados como instrumentos de promoção folders de serviços, fotografias de visitas técnicas, projetos e vídeos de atividades realizadas.

Uma vez disponibilizado hiperlinks ou quaisquer novas informações de maneira criativa e útil, que facilitem a vida do usuário e desperte a curiosidade dos mesmos, o marketing se 
beneficiará das novas formas de circular as informações propiciadas pela internet (SILVA, 2008).

Na personalização, quinto indicador verificado, constatou-se a existência de cadastros e serviços que personalizam as necessidades e os desejos dos indivíduos no website. Diante de um mercado com diversos incentivos, os equipamentos culturais tendem a desempenhar um papel para além de fonte de informação. Mais o índice ainda é baixo, sendo que os arquivos são representados com $41 \%$ de personalização enquanto que nas bibliotecas, o índice é de 33\%. Para Caldas (2005, p. 3) "partiria da análise de variados recursos existentes visualizando-se sua melhor utilização - como pessoal, tecnológico e institucional - facilitando-se assim a sua ordenação para com os objetivos pretendidos pela organização".

Neste segmento, um exemplo visualizado foi no Arquivo Público do Estado de São Paulo. Que mediante solicitação de cadastro, tende a ofertar conteúdos enviados aos $e$-mails particulares dos internautas. Na pesquisa personalizada, os refinamentos de busca para procura nos acervos foram de apenas sete instituições. Os metadados a serem preenchidos tendem a agregar agilidade na procura em documentos que estão disponíveis virtualmente. Neste caso, deve haver bancos de dados com os acervos e coleções disponíveis na plataforma digital. A biblioteca do Amazonas possui uma página "extra" voltada à biblioteca virtual, que garante o acesso aos acervos, às fotografias, jornais e revistas vinculadas ao Estado.

O último indicador de Marketing Digital, denominado relacionamento, possui como foco os vínculos comunicativos que a instituição oferta ao sujeito e assim, assegura um diálogo para além dos serviços disponíveis no website. Para as bibliotecas, apresentou-se um $60 \%$ de uso de relacionamento via internet em websites e como formas de extensão comunicativa com o individuo. No que tange ao arquivo, o índice é baixo, com apenas $42 \%$ do indicador analisado.

A potencialidade de plataformas como Facebook, Twitter e Youtube, contribuem de forma a auxiliar na pesquisa, uma vez que, reconfigura o desenvolvimento social baseados em hipertextos, memória e narrativa oral.

Utilizou-se do gráfico 2 para demonstração do uso dos indicadores de marketing digital em cada website do Estado. 
Gráfico 2 - Apropriação do Marketing Digital por Estado Brasileiro

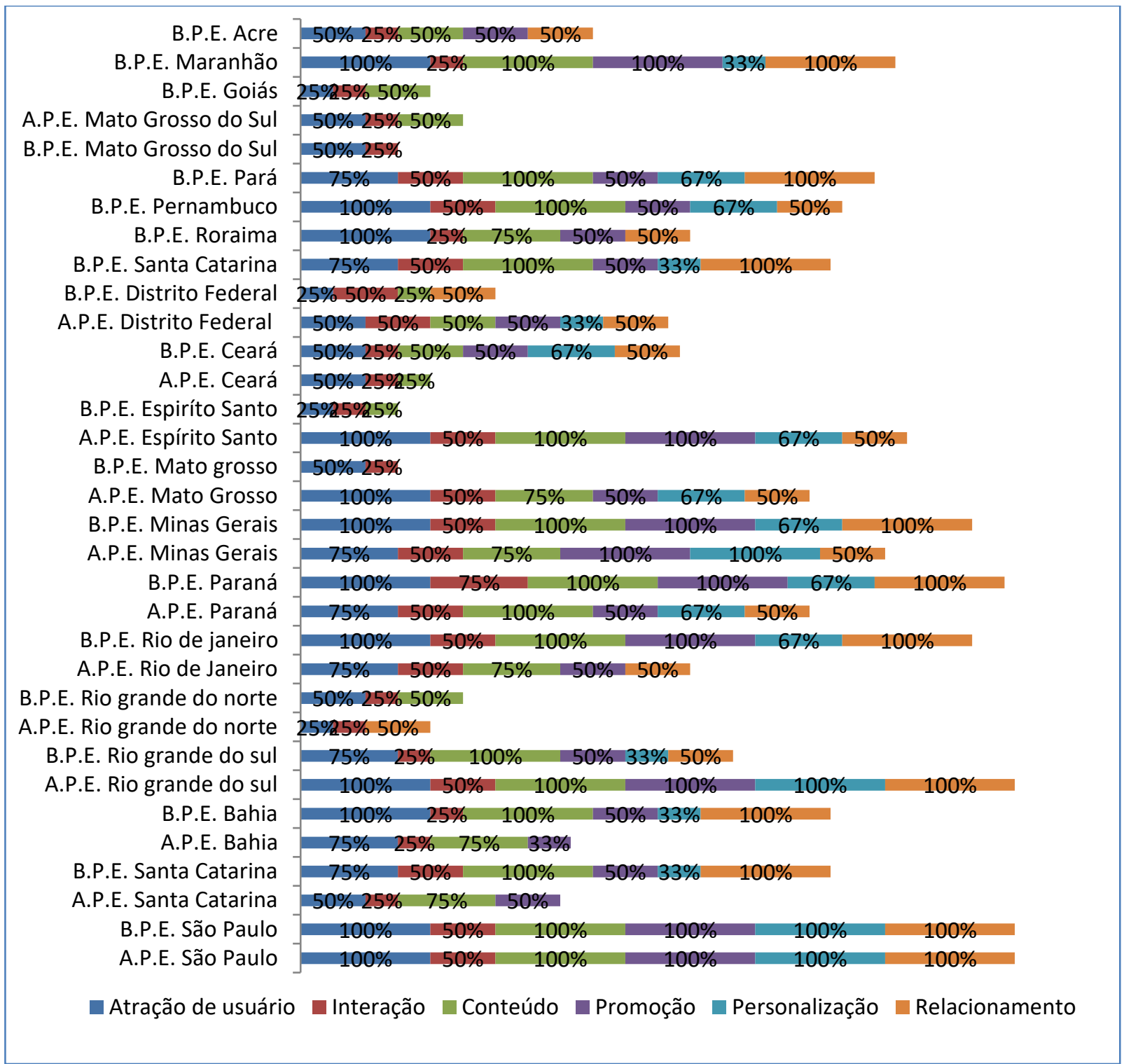

Fonte: Elaborado pelos Autores

Demonstrou-se nos índices que as menores porcentagens de uso do marketing digital estão entre as bibliotecas de Santa Catarina, Espírito Santo, Rio Grande do Norte, Mato Grosso do Sul, Mato Grosso e Goiás.

Em arquivos, os menores índices são de Santa Catarina, Rio Grande do Norte, Mato Grosso do Sul e do Ceará. A inserção da internet em função dos serviços arquivísticos coloca questões referentes à materialidade, digitalização e aos conteúdos de documentos disponíveis em rede. Neste sentido, importa verificar até que ponto os arquivos utilizam a internet como folder institucional limitando-se expor dados.

Em contrapartida, as bibliotecas de Minas Gerais, Paraná, Rio de Janeiro e de São Paulo, foram as que obtiveram altos índices de uso do marketing digital e de prestação de serviços ao 
usuário em rede. Isto porque, integram o usuário ao trabalho colaborativo das bibliotecas públicas e mantém um espaço informacional de qualidade em um ambiente digital de informação. Nos arquivos, os Estados do Espírito Santo, do Paraná, do Rio Grande do Sul e de São Paulo, utilizam da internet para transferir a informação permitindo maior possibilidade de acesso bem como visibilidade institucional e social. Os Estados de São Paulo e de Minas Gerais tiveram maiores impactos nas duas instituições no contexto de marketing digital. Isso porque, utilizam de instrumentos que agreguem dinamicidade, conteúdos e serviços online que melhor se relacionam com o usuário potencial.

Segundo pesquisa pelo IBGE, no Estado de São Paulo a produção industrial brasileira é concentrada em $36 \%$. No setor de pesquisa e desenvolvimento, o Estado dispõe de uma rede intensiva de universidades, centros de pesquisa incubadora, respondendo por $86 \%$ dos investimentos. Neste contexto, os Arquivos e as Bibliotecas são indispensáveis para o acompanhamento e execução das atividades do Estado, visando prestar serviços de orientação aos órgãos do Legislativo, Executivo e Judiciário, referente aos afazeres de acesso e uso da informação.

Skerrett (2017) diz que a criação de serviços que usufruem de tecnologias devem resolver os problemas dos clientes ao mesmo tempo que aplicam oportunidades de crescimento. Isto porque, o comportamento do usuário se modificou com a inserção da internet em quase todos os afazeres do cotidiano. Skerett aponta que as empresas - lucrativas ou não - devem olhar para este comportamento que modifica o mercado e auxilia na criação de negócios.

\section{Considerações finais}

Os websites dos arquivos ampliaram o paradigma de custódia para uma póscustodialidade e permitem o acesso e uso de recursos por meio da disponibilização de serviços e produtos no ambiente digital.

Entretanto, na realidade verificada nesta pesquisa, compreendeu-se que algumas ineficiências internas e externas prejudicam o contexto dos Arquivos e Bibliotecas na web. Dentre eles, destacam-se: a falta de recursos humanos e financeiros e desamparo estrutural na web, que tornam-se em grande parte, limitadora de serviços e uso da informação nestes websites. 
A complexidade, diga-se "analógica", para com a entidade e os documentos físicos, aumentou perante o vínculo e representação das mesmas na internet. A pesquisa confirma que ambas as instituições públicas, precisam compreender a dimensão digital como parte das atividades concernentes ao funcionamento do Estado. Neste contexto, destaca-se a Lei de Acesso à Informação (LAI), e que segundo o seu art. $8^{\circ}$, afirma que entidades e órgãos públicos devem publicar na internet informações públicas de interesse coletivo e geral, tais como: programas, projetos, ações, obras e atividades, repasses, execução orçamentária e financeira, respostas e perguntas mais frequentes da sociedade, entre outras.

Percebeu-se que os serviços e produtos disponibilizados no ambiente digital, são prejudicados pela falta de um norteamento para atender aos novos sujeitos. Os índices demonstrados são baixos, uma vez que os recursos digitais que a internet oferece aliados ao marketing digital, poderiam potencializar o vinculo existencial da instituição em uma nova era de serviços e produtos ao alcance do usuário global.

Henderson (2005) relata que ao utilizar marketing digital em bibliotecas ou quaisquer unidades que prestam serviços ao Estado, podem-se obter informações para melhor atender as necessidades e desejos do público potencial. Entre elas, destacam-se: dados demográficos dos usuários, idades, gênero, interesses, tempo de visitação, empréstimos. Estas informações, então, serão utilizadas para segmentação de mercado e para a tomada de decisões como o estabelecimento de vínculos entre serviços e produtos que se adequem ao cliente e previsões de necessidades do público.

Decidir qual serviço disponibilizar e qual público atender é um princípio essencial pois, os conteúdos disponibilizados em websites são tratados comumente. Métodos de análise e de trabalho com os dados fornecidos por meio do marketing digital alcançariam com melhor precisão os efeitos dos serviços disponibilizados e se estes alcançam as necessidades dos usuários.

O marketing digital, como uma das formas de norteamento de gestão na internet, pode alcançar um público em larga escala e promover a promoção e utilização de recursos para a prestação de serviços de qualidade. Tal possibilidade deve ser pensada juntamente com um plano estratégico da administração da entidade, visto que, a aplicação do método, somente, não satisfará as necessidades do público e da instituição sem um trabalho de digitalização dos documentos necessários, softwares adequados às necessidades dos usuários e das bibliotecas; equipes multidisciplinares que acompanhem os resultados rastreáveis do investimento; políticas 
que direcionam as ações das instituições na web; e parcerias interoperáveis de outros ambientes tecnológicos.

Em São Paulo, os índices de uso do marketing digital em arquivos e bibliotecas foram altos. A participação das intuições na atual administração está comprometida com a legislação vigente e com a transparência da gestão pública. Assim, reflete no desenvolvimento de uma ambiência digital capaz de atuar junto aos demais órgãos da administração estadual no desenvolvimento da gestão pública.

No entanto, com o colapso nas contas públicas do Mato Grosso do Sul, os investimentos foram insuficientes para manter um nível proporcional de marketing digital em arquivos e bibliotecas. O Estado, mesmo zerando o número de municípios sem bibliotecas públicas, carece de um fortalecimento de ações de promoção à disponibilização de website para a atuação em função da administração pública.

Logo, o Marketing Digital proposto por Ferreira (2016) e aplicado nas unidades requer uma nova realidade de ações estratégicas de relacionamento, disponibilização de conteúdos, interação, promoção e atração de usuários como formas de aderirem instituições que não visam lucro no contexto digital. Além disso, aborda-se oportunidades de trabalhos colaborativos, de modo a incluir, informacionalmente, seus usuários como participantes ativos nas Bibliotecas e Arquivos.

\section{Referências}

AMARAL, S. A. Marketing: abordagem em unidades de informação. Brasilia: Thesaurus 1998, 244p.

ARAÚJO, C. A. Á. Arquivologia, Biblioteconomia, Museologia e Ciência da informação: o diálogo possível. Brasília: Briquet de Lemos: São Paulo: Associação Brasileira de Profissionais da Informação, 2014.

BARROS, M. H. T. C. Disseminação da informação: entre teoria e a prática. Marília: [s.n.], 2003. 112 p.

CALDAS, R. F. Composto de marketing na abordagem das unidades de informação. In: SIMPÓSIO EM FILOSOFIA E CIÊNCIA, 6., 2005. Universidade e contemporaneidade: produção do conhecimento e formação profissional. Marília: Comissão Permanente de Publicações, UNESP, 2005. v. 1.

CASTELLS, M. A sociedade em rede. 5. ed. São Paulo: Paz e Terra, 1999. 
CARDOSO, G; CASTELLS, M. A sociedade em rede: do conhecimento à acção política. Imprensa Nacional Casa da Moeda: Belém-Portugal, 2005.

CHLEBA, M. Marketing digital: novas tecnologias \& novos modelos de negócio. São Paulo: Futura, 1999.

CINTRA, F. C. Marketing digital: a era da tecnologia on-line. Investigação, Franca, v. 10, n. 1, 2010. Disponível em:

$<$ http://publicacoes.unifran.br/index.php/investigacao/article/view/147>. Acesso em: 12 jun. 2017.

CRITTENDEN, V.; CRITTENDEN, W. Digital and social media marketing in business education implications for the marketing curriculum. Journal of Marketing Education, v. 37, n. 3, 2015.

DZIEKANIAK, G. V. et al. Avaliação de websites de bibliotecas universitárias da região sul. Biblos, Rio Grande, v. 19, p. 171-200, 2006. Disponível em:

$<$ http://repositorio.furg.br/bitstream/handle/1/262/75.pdf?sequence=1 >. Acesso em: 12 mar. 2017.

FERREIRA, L. H. G. Indicadores de marketing digital para websites de arquivos públicos estaduais. 2016. Trabalho de Conclusão de Curso (TCC) - Universidade Estadual Paulista, Marília, 2016.

HENDERSON, K. Marketing strategies for digital library services. Library Review, v. 54, n. 5, p. 342-345, 2005. Disponível em:

<https://search.proquest.com/docview/218318246?accountid=8112>. Acesso em: 12 jun 2017.

KAPLO, M; LUNDKVIST, A. How to stay relevant in a time of digital marketing: Investigatingthe perspectives of marketing agencies and business firms. [s.l.]: Jönköping International Business School: 2015.

KELLY, B. et al. New media butsameoldtricks: food marketing tochildren in the digital age. Currentobesityreports, v. 4, n. 1, p. 37-45, 2015.

KOTLER, P. Administração de marketing: análise, planejamento, implementação e controle. 5. ed. São Paulo: Atlas, 1998.

MARIZ, A. A. A informação na internet: arquivos públicos brasileiros. Rio de Janeiro: FGV, 2012168 p.

NAIK, U.; SHIVALINGAIAH, D.; Comparative study of Web 1.0, Web 2.0 and Web 3.0. 2008. Disponível em <http://ir.inflibnet.ac.in/handle/1944/1285> Acesso em: 13 mar. 2017.

RIBEIRO, F. Os arquivos na era pós-custodial: reflexões sobre a mudança que urge operar. Boletim cultural - Câmara Municipal de Vila Nova de Famalicão, v. 5, n. 1, p. 129-133, 2005. Disponível em: <http://ler.letras.up.pt/uploads/ficheiros/artigo10091.pdf>. Acesso em: 12 mar. 2017.

SANTAELLA, L. Matrizes da linguagem visual e pensamento: sonora visual verbal. 3. ed. São Paulo: Iluminuras, 2001. 
SANTOS, H. M.; FLORES, D. O documento digital no contexto das funções arquivísticas. Páginas a\&b, Porto, série 3, n. 5, p. 165-177, 2016. Disponível em <http://ojs.letras.up.pt/index.php/paginasaeb/article/view/1477>. Acesso em: 12 jun. 2017.

SANTOS, P. X. A dimensão política da disseminação da informação através do uso intensivo das tecnologias de informação e comunicação uma alternativa à noção de impacto tecnológico. DataGramaZero, v. 5, n. 4, 2004.

SÁ-SILVA, J. R.; ALMEIDA, C. D.; GUINDANI, J. F. Pesquisa documental: pistas teóricas e metodológicas. Revista Brasileira de História \& Ciências Sociais, v. 1, n. 1, 2009.

SILVA, N. Marketing viral: quando os internautas são a melhor propaganda. 2008. Dissertação (Mestrado em Comunicação) - Faculdade de Comunicação, Universidade de Brasília, Brasília, 2008.

SILVA, R. C.; CALDAS, R. F. Arquivos híbridos: reflexões para a transição de estruturas organizacionais. Páginas a\&b, Porto, série 3, n. 5, p. 146-164, 2016. Disponível em <http://ojs.letras.up.pt/index.php/paginasaeb/article/view/1476>. Acesso em: 12 jun. 2017.

SILVA, A. M.; RIBEIRO, F. Das "ciências" documentais à ciência da informação: ensaio epistemológico para um novo modelo curricular. Porto: Afrontamento, 2002.

SKERRETT, D. Focusing on your customer experience is great for business. EContent, v. 40, n. 3, p. 12-13, 2017. Disponível em:

<https://search.proquest.com/docview/1896758805?accountid=8112>. Acesso em: 12 jun. 2017.

STRAUSS, J.; FROST, R. E-marketing. 7. ed. Prentice Hall: Routledge. 2012. 496p.

ZEISSER, M.; WAITMAN, R. Organizing today for the digital marketing of tomorrow. Journal of Interactive Marketing, v. 12, n. 1, 1998. 